\title{
Conhecimento e Currículo na formação dos Intelectuais
}

\author{
Iza Helena Travassos Ferraz de Araújo ${ }^{1}$, Maria Gorete Rodrigues Cardoso²
}

${ }^{1}$ Universidade Federal do Pará - UFPA, Instituto de Ciências da Educação, Rua Augusto Corrêa, 01, CEP: 66075-110, Belém, PA, Brasil. Email: izahelena@ufpa.br

${ }^{2}$ Universidade Federal do Pará - UFPA, Campus Universitário de Bragança, Faculdade de Educação, Alameda Leandro Ribeiro, s/n, CEP: 68600-000, Bragança, PA, Brasil. Email: goreterc@ufpa.br

ISSN 2448-0479

Resumo - Esta pesquisa se constitui num ensaio teórico que tem como objeto de estudo o papel do conhecimento e do currículo para a formaçáo dos intelectuais. A investigação se desenvolve a partir de uma bricolagem dos conceitos de intelectuais propostos por Gramsci (1982) e Bauman (2010). As questōes levantadas são: o que entendemos por intelectuais? No que consiste a formação dos intelectuais em uma sociedade? Quais as relaçóes entre conhecimento, currículo e a formação dos intelectuais? Que implicações estas relaçôes têm na seleção e organização dos conhecimentos que constituem os currículos? Os objetivos da investigaçấo são refletir sobre as relações entre conhecimento, currículo e formação dos intelectuais e revelar suas implicaçôes na seleção dos conhecimentos e organização dos currículos escolares. $\mathrm{Na}$ primeira parte do trabalho realizamos uma leitura dos conceitos de intelectuais tradicionais e orgânicos sob a ótica das metáforas do legislador e do intérprete, com destaque para a função dos intelectuais na sociedade e na educação. Em seguida, desenvolvemos uma discussão acerca do vínculo entre conhecimento e currículo, fundamentadas em Lopes e Macedo (2011; 2012) e Apple (1997; 1999; 2000). Por fim, realizamos o cotejamento entre a função dos intelectuais na sociedade e os vínculos entre currículo e conhecimento escolar, especificamente, nas perspectivas de formação. Os resultados indicam que os modos de conceber os intelectuais e sua formação em determinado tempo e espaço têm influências na seleção e na negociação dos conhecimentos que irão constituir o currículo escolar, e, ainda, que a formação dos intelectuais de diversos tipos e em distintos contextos imprimiu traços no currículo que ainda se fazem presentes até os dias de hoje.

Palavras-chave: Conhecimento. Currículo. Formação dos Intelectuais.

\begin{abstract}
This research is a theoretical analysis about knowledge and curriculum in the training of intellectuals, whose approach is given from abricolage of intellectual concepts proposed by Gramsci (1982) and Bauman (2010). The questions raised are: what we mean by intellectuals? How is the training of intellectuals in a society? What are the relationships between knowledge, curriculum and training of intellectuals? What impact these relationships have in the selection and organization of knowledge that constitute the curriculum? The objectives of the research are to reflect on the relationship between knowledge, curriculum and training of intellectuals and reveal its implications in the selection of knowledge and organization of school curricula. The research reveals the textual path that develops, initially, a reading of the concepts of traditional and organic intellectuals from the perspective of the metaphors of the legislator and the interpreter, especially about the function of intellectuals in society and education. Then considerations are presented about the link between knowledge and curriculum, grounded
\end{abstract}


on Lopes and Macedo (2011; 2012) and Apple (1997; 1999; 2000). Finally, carried out the coping between the intellectual function in society and the links between curriculum and school knowledge, specifically in training prospects. Then considerations are presented about the link between knowledge and curriculum, grounded on Lopes and Macedo (2011; 2012) and Apple (1997; 1999; 2000). Lastly, carried out the coping between the intellectual function in society and the links between curriculum and school knowledge, specifically in training prospects. The results indicate that the ways of conceiving the intellectuals and their training at any given time and space, have influences in the selection and negotiation of the knowledge that will be part of the school curriculum, under different curricular perspectives, and that the training of intellectuals of various types and in different contexts left traces in the curriculum that still permeate our educational context.

Keywords: Knowledge. Curriculum. Training of intellectuals.

Recebido em: 23 de março de 2016.

Aprovado em: 22 de maio de 2016.

\section{INTRODUÇÃO}

Conhecimento e currículo são temas pertencentes ao campo dos Estudos Curriculares e que permitem diversas abordagens a partir da multiplicidade de enfoques teórico-metodológicos produzidos pelo pensamento curricular contemporâneo. A discussão sobre a seleção dos conhecimentos e saberes que devem compor o currículo escolar sempre esteve na pauta das políticas educacionais, dos sistemas educativos e das escolas. Tal seleçáo, em determinados momentos e contextos histórico, cultural e social, tem buscado responder a diversos propósitos, conforme os objetivos e as finalidades colocadas à escola. Pois, ao selecionar alguns conhecimentos como essenciais, outros ficam de fora. Assim uma determinada visão de conhecimento, de currículo e de cultura é legitimada, enquanto que outras são negadas e/ou invisibilizadas.

Nosso interesse em relacionar o debate curricular à questão da formaçáo dos intelectuais advém da realização de estudos históricos sobre o modelo curricular que se tornou hegemônico nas escolas públicas secundárias no final do século XIX, o qual tinha como principal objetivo formar as elites dirigentes, ou seja, formar aqueles que deveriam exercer as funçôes de intelectuais naquele momento.
No Brasil, após a expulsão dos jesuítas, houve uma tentativa de estruturar e organizar o ensino secundário calcado no modelo educacional francês, cujo marco está na fundação do Colégio Pedro II, posteriormente denominado de Ginásio Nacional, no ano de 1837, no Rio de Janeiro. O ensino do Colégio Pedro II era voltado para a formação de uma elite intelectual e seu currículo se constituía na referência para os demais ginásios espalhados em diversas localidades do país, que deveriam tomá-lo parâmetro para equiparar seus currículos como condição para obter status em suas províncias/estados.

Os alunos que estudavam nos ginásios eram fortes candidatos a ingressarem no ensino superior e, consequentemente, a se tornarem os intelectuais da elite local da época, ocupando cargos políticos e exercendo atividades econômicas de destaque. Exemplo disso pode ser notado na criação do Ginásio da Capital, na cidade de São Paulo, em 1892, o qual fazia parte do projeto da elite política estadual para formar os quadros políticos do futuro. Foi neste Ginásio que estudaram algumas personalidades brasileiras como Júlio Prestes de Albuquerque, ex-governador de São Paulo, e Armando Sales de Oliveira, fundador da Universidade de São Paulo, em 1934 (ABUD, 1996). Segundo Abud (1996, p. 495),

Os legisladores de São Paulo baseavam-se nos
princípios científicos e positivistas, ora se fun-
damentando em experiências européias, ora em
experiências norte-americanas, e consideravam
a educação como um pilar, como um ponto de
sustentaçáo do novo Estado. A valorização do
conhecimento científico, a introduçáo de novas
técnicas face à modernização constituía o ideal
escolar para a classe dirigente. A escola média
se organizou para receber uma clientela específi-
ca, constituída de filhos de fazendeiros de café,
profissionais liberais, que formavam as camadas
médias urbanas.

Apesar dos republicanos propalarem a educação como um direito de todos e da educaçáo escolar ser considerada cada vez mais um fator de promoção de desenvolvimento econômico do país, a implementação dos ginásios ao final do século XIX e início do século XX, atendia apenas a uma pequena parcela dos estudantes. Dessas instituiçóes é que se esperava que surgisse a elite intelectual do país. Nesse período, os ginásios, como centros irradiadores do ensi- 
no secundário brasileiro, assumiram um importante papel no processo de escolarizaçáo e de formaçáo de um pensamento científico dos intelectuais da sociedade brasileira.

Mas o que entendemos por intelectuais? No que consiste a formação dos intelectuais em uma sociedade? Quais as relaçóes entre conhecimento, currículo e a formaçấo dos intelectuais? Que implicaçôes estas relaçôes têm na seleção e organização dos conhecimentos que constituem os currículos escolares? Estas são as questóes que nos motivaram a delinear como objeto de estudo conhecimento e currículo na formação dos intelectuais, sobre o qual faremos uma incursão histórica não factual e não linear. Os objetivos da investigação são refletir sobre as relaçôes entre conhecimento, currículo e formação dos intelectuais e revelar suas implicaçôes na seleçâo dos conhecimentos e organização dos currículos escolares.

$\mathrm{Na}$ tentativa de responder às questôes anunciadas, optamos por fazer uma leitura dos conceitos de intelectuais tradicionais e orgânicos estabelecidos por Gramsci (1982) sob a ótica das metáforas do legislador e do intérprete propostas por Bauman (2010). A escolha de pensadores com visóes e perspectivas distintas de mundo e educação foi motivada pelo desejo de "justapor diferentes formas de análise de forma útil, produtiva e nada monótona", bem como, "mostrar as relações entre elementos heterogêneos" (RIBEIRO, 2013 , p. 55). Ensaiamos neste texto uma bricolagem de perspectivas teóricas para a discussão do objeto, sem, contudo, pretender construir verdades sobre o assunto. A bricolagem pode ser vista como espécies de peças, de fragmentos que

estivessem escondidas à espera de um investigador, o que se pretende é entender a sua construção e questionar como os diversos agentes sociais produzem e reproduzem o que é imposto pelos discursos hegemônicos. Ora, teorias e conhecimentos nada mais são do que artefatos culturais e linguísticos. Uma vez que a interpretação está imbricada na dinâmica social e histórica que moldou o artefato cultural sob análise, a bricolagem reconhece a inseparabilidade entre objeto de pesquisa e contexto. Consequentemente, a linguagem e as relaçóes de poder assumem a posição central nas interpretaçóes da realidade, pois se constituem como mediadores fundamentais na contemporaneidade (NEIRA; LIPPI, 2012, p. 611).
Enquanto pesquisadoras da área da educação e do currículo já tínhamos conhecimento das ideias de Antônio Gramsci e de suas influências no campo dos Estudos Curriculares a partir de uma perspectiva crítica. Ao encontrar Zygmunt Bauman ampliamos nosso olhar no que se refere ao conceito de intelectuais e suas relaçôes com a sociedade e com a educaçẫo. Com base nessas referencias é procuramos fazer, inicialmente, uma leitura dos intelectuais orgânicos a partir da metáfora do legislador, mas, com o avanço da pesquisa, superamos esta tácita equiparação, ampliando nosso olhar sobre conhecimento, currículo e formação dos intelectuais.

Desta forma, iniciamos este texto com uma incursão nos conceitos de intelectuais apresentados por Gramsci (1982) e Bauman (2010), destacando a função dos intelectuais na sociedade e, consequentemente, na educação. Num segundo momento, apresentamos os vínculos entre conhecimento e currículo fundamentadas nas teorizaçôes curriculares de Lopes e Macedo $(2011 ; 2012)$ e de Apple (1997; 1999; 2000). Em seguida, fazemos o cotejamento entre a função dos intelectuais na sociedade e os vínculos entre conhecimento e currículo, enfatizando as perspectivas de formação a partir de contribuições de Goodson (2001) e Ribeiro (2013). Por fim, apresentamos nossas consideraçôes acerca do objeto com perspectivas de pesquisas futuras.

\section{OS INTELECTUAIS SOB LENTES DISTINTAS}

Para Gramsci (1982, p. 142), "toda geração educa a nova geração, isto é, forma-a; a educação é uma luta contra a natureza, a fim de dominá-la e de criar o homem 'atual' à sua época", ou seja, para a sobrevivência de uma sociedade é necessário que a uma geração repasse à geração seguinte os seus valores, suas crenças, seus conhecimentos e suas práticas. È através da educação que o homem se torna homem, membro dessa sociedade. Porém, esse processo educativo dos jovens não é natural e/ou mesmo pacífico, há conflitos e discórdia, uma luta contra a natureza, características próprias do fenômeno educativo. Além disso, há um jogo de interferências de classes sociais, no qual jovens deixam de ser dirigidos por velhos de uma classe para serem dirigidos por velhos de outra classe ${ }^{1}$.

${ }^{1}$ Ibidem. 
Quem são os "velhos” citados por Gramsci? São aqueles que têm posição de dirigentes nos grupos sociais ou que são designados por estes para a formação de uma nova geração do mesmo grupo. Porém, o termo dirigir é distinto do termo formar, Embora estes termos não sejam necessariamente excludentes e desconectados. Posto isso, é necessário que se faça uma reflexão sobre a formação dos intelectuais que, além de responsáveis pela educação das novas geraçóes, são partícipes ativos desses conflitos entre as classes, uma vez que os intelectuais são parte integrante de um grupo social.

Para compreendermos o conceito de intelectual é necessário que o situemos no conjunto do sistema de relaçôes sociais no qual as atividades intelectuais se encontram (GRAMSCI, 1982). A categoria intelectual deve ser tratada como um elemento estrutural no interior da figuraçáo social (BAUMAN, 2010). O conceito de intelectual deve estar relacionado a um contexto social, político, cultural e, consequentemente, educativo, em diferentes épocas. Portanto, uma tentativa de compreensão mais ampla dessa categoria passa, inevitavelmente por questôes de ordem históricas.

Zygmunt Bauman (1925, Polônia) é um sociólogo contemporâneo conhecido pelo conceito de modernidade líquida ${ }^{2}$. Em seu livro intitulado "Legisladores e Intérpretes", o autor recorre à história para explicar o conceito de intelectual. Fundamenta seus argumentos em pesquisas que contemplam a temática desde o homem primitivo até o homem pós-moderno. Essa trajetória é marcada pela argumentação sobre como eram autodefinidos os intelectuais em cada contexto. Bauman utiliza também a gênese da palavra intelectual e estabelece uma relaçâo entre os protótipos de ideias e o nascimento das mesmas em determinados tempos históricos, além de estabelecer uma relação entre intelectuais e educação.

Antônio Gramsci (1891-1937) é um filósofo italiano, marxista, cujos escritos foram reunidos e publicadas em diversos livros. Para Nosella (2010, p. 31)

De fato, hoje Gramsci é cada vez mais reconhecido como testemunha crítica dos grandes acontecimentos da primeira metade do século XX,

\footnotetext{
${ }^{2} \mathrm{Na}$ modernidade líquida o indivíduo passa do estado de agente passivo para o de agente ativo. Sua liberdade de escolha, porém, se torna ao mesmo tempo uma bênção e uma maldição, dado que recai sobre ele a responsabilidade de seus atos e açôes. BAUMAN, Z.. Modernidade Líquida. Rio de Janeiro: Jorge Zahar, 2001.
}

da $1^{\text {a }}$ Guerra Mundial, da Revolução Russa, da grande esperança revolucionária do pós-guerra e da ascensão do fascismo. Nos seus escritos, as conjunturas históricas se iluminam de ciência política, e esta, por sua vez, vem se enriquecendo de novos conceitos no exercício da análise das conjunturas. Aliás, esse movimento de reflexão (entre conjuntura e ciência) é talvez seu melhor legado metodológico.

Dentre suas obras, analisamos o livro "Os intelectuais e a organizaçáo da cultura", dividido em quatro partes, sendo a primeira intitulada "Contribuições para uma história dos intelectuais". Esta seção é constituída por uma reflexão sobre a formação dos intelectuais, seguida de notas esparsas sobre intelectuais em diferentes contextos. Para iniciarmos a discussão, partiremos da noçâo de intelectuais nas acepçóes de Bauman e Gramsci.

Gramsci (1982, p. 7), afirma que "todos os homens são intelectuais, mas nem todos os homens desempenham na sociedade a função de intelectuais", ou seja, toda atividade física, profissional e cotidiana move no indivíduo um "mínimo de atividade intelectual criadora", uma vez que o "pensar", assim como o trabalho, é o que torna o homem, homem. Por outro lado, Bauman (2010, p. 16) corrobora com Gramsci quando afirma que "em qualquer lugar e em qualquer tempo, 'os intelectuais' são constituídos por um efeito combinado de mobilização e autorrecrutamento". Isto é, para desempenhar a função de intelectual na sociedade é necessário estar impulsionado para desenvolver tal atividade, bem como, estar engajado em algum objetivo.

Ambos também refletem sobre a diferenciação entre os intelectuais e os não-intelectuais, que corresponde "tão-somente à imediata função social da categoria profissional dos intelectuais na atividade profissional específica" (GRAMSCI, 1982, p. 7), cuja linha é "traçada e retraçada pelas decisóes de tomar parte num modo particular de atividade" (BAUMAN, 2010, p. 16). Para ambos os autores, o conceito de intelectual supera a visão tradicional e vulgarizada "fornecida pelo literato, pelo filósofo, pelo artista” (GRAMSCI, 1982, p. 8), pois eleva-se "acima da preocupação parcial com a profissão ou gênero artístico da pessoa, para incumbir-se das questóes globais sobre verdade, o juízo e o gosto da época" (BAUMAN, 2010, p. 16).

Gramsci (1982) classificou os intelectuais em dois grupos - os intelectuais orgânicos e os intelectuais 
tradicionais - a partir da função desempenhada pelos mesmos em cada grupo social. Segundo o autor, a funçâo dos intelectuais orgânicos é dar "homogeneidade e consciência da própria função, no campo econômico, político e social"3. Ferreira (2011, p. 30) afirma que os intelectuais orgânicos "assumem funções em diversos tipos de territórios, urbanos, rurais, econômicos, políticos e sociais", desenvolvendo "uma funçẫo organizadora na sociedade, seja no campo da produçâa, da cultura ou na administração política". Segundo Nosella (2010, p. 57-58), orgânicos na Itália equivale ao termo quadros em língua francesa, ele destaca que

\begin{abstract}
Os orgânicos, na Itália, são as pessoas diretamente engajadas em na organização de uma instituição; no caso, de um Partido. Ora, formar "os orgânicos", programar atividades formativas e de atualização para os "orgânicos", constituía práxis ordinária de toda instituição e de todo partido.
\end{abstract}

Quanto aos intelectuais tradicionais, estes são pertencentes a um grupo social essencial e são "representantes de uma continuidade histórica que não fora interrompida nem mesmo pelas mais complicadas e radicais modificaçóes das formas sociais e políticas" (GRAMSCI, 1982, p. 5). Na interpretação de Nosella (2010), Gramsci pensava nos intelectuais tradicionais como sendo os professores, os advogados, os cientistas, os jornalistas, os escritores, os artistas, os religiosos que não se engajavam diretamente em seus quadros, contudo,

Gramsci toma aos poucos posição contrária: reconhece aos intelectuais tradicionais importantíssima funçâo na luta hegemônica do Partido, se interessa de interagir e discutir com eles, acha que é possível e desejável programar atividades formativas realizadas por eles e para eles, sem que abandonem seu modo específico-tradicional de trabalhar (de estudar, de pesquisar, de divulgar etc.), isto é, sem que deixem de ser "tradicionais", no sentido de operarem conforme o estatuto ético e científico tradicional da sua categoria para se tornarem administrativamente $\mathrm{e}$ politicamente orgânicos (ibidem, p. 58).

Deste modo, o papel dos intelectuais em uma determinada sociedade depende da função dos mes-

${ }^{3}$ ibidem, p. 3 mos no grupo social ao qual estão inseridos. Para Gramsci (1982, p. 8-9)

\begin{abstract}
Uma das mais marcantes características de todo grupo social que se desenvolve no sentido do domínio é sua luta pela assimilaçấo e pela conquista "ideológica" dos intelectuais tradicionais, assimilação e conquista que são tão mais rápidas e eficazes quanto mais o grupo em questão elaborar simultaneamente sues próprios intelectuais orgânicos.
\end{abstract}

Para Bauman (2010, p. 18) é necessário a "compreensão da natureza associada ao trabalho intelectual e a seu propósito", este autor nos apresenta duas visóes de mundo: uma tipicamente moderna e outra pós-moderna. $\mathrm{Na}$ visão tipicamente moderna, o mundo é uma totalidade em essência ordenada que possui um padrão desigual de distribuição de probabilidades. Essas características permitem a explicação dos fatos que, se correta, se torna uma ferramenta de predição e controle,

Esse controle ("domínio da natureza", "planejamento" ou "desenho" de sociedade) é quase de imediato associado à açáo de ordenamento, compreendida como a manipulação de probabilidades (tornando alguns eventos mais prováveis, outros menos prováveis). Sua efetividade depende da adequaçáo do conhecimento da ordem "natural". Tal conhecimento adequado é, em princípio, alcançável. (ibidem, p. 18)

Sob esta ótica é que devemos compreender a metáfora do legislador apresentada por Bauman, como a que melhor caracteriza a estratégia moderna do trabalho intelectual. O intelectual como legislador é aquele que faz afirmaçóes autorizadas e autoritárias e arbitra diante de opiniôes controversas. Essas afirmações são legitimadas pelo conhecimento (objetivo) superior, que somente os intelectuais têm acesso. Surge então uma categoria especializada para o exercício da função intelectual que está em conexáo com todos os grupos sociais, mas especialmente ligada com o grupo social dominante (GRAMSCI, 1982).

Diante de uma visão moderna do mundo, Bauman (2010, p. 20) destaca o que denomina de profissōes intelectuais (cientistas, filósofos, morais, estetas), que se tornam "proprietárias coletivas de um saber de relevância direta e crucial para a manutençâo e aper- 
feiçoamento da ordem social”. Gramsci (1982), por sua vez, afirma que os detentores do poder ou os grupos dominantes é que, tradicionalmente, formaram uma camada de intelectuais. Dessa forma, os intelectuais se tornaram "comissários" para o exercício das funçôes subalternas da hegemonia social e do governo político. Os intelectuais são os responsáveis pelo consenso "espontâneo" dado pelas grandes massas da população e pela coerção social estatal que assegura "legalmente" a disciplina dos grupos que não "consentem" ${ }^{\prime}$. São os intelectuais como legisladores que se tornaram os responsáveis pela "vigilância assimétrica" estabelecida pela sociedade moderna, materializada pelos asilos, manicômios, prisóes e escola.

Os legisladores são comissários do grupo dominante e determinam regras (ou leis), formulam conceitos, fazem conquistas ideológicas, criam hegemonia social e organizam políticas econômicas e culturais. Essa atividade de "legislar" requer conhecimento altamente especializado e de alta cultura (FERREIRA, 2011), cujo acesso "se dá graças a regras de procedimento, garantindo que se alcance a verdade, que se chegue a um juízo moral válido e se selecione um gosto artístico apropriado" (BAUMAN, 2010, p. 20). Surgem então os "intelectuais propriamente ditos", que são responsáveis "pela formulação de regras de proceder e pelo controle de sua aplicação correta"s. Porém, a elaboração de uma camada de intelectuais ocorre de acordo com processos históricos tradicionais. Para Ferreira (2011, p. 26):

Gramsci analisa o papel dos intelectuais e da escola no centro das mudanças estruturais do capital, e argumenta a necessidade que a nova organização dos processos de trabalho e de estilo de vida impóe à formação psicofísica dos indivíduos, isto é, a formação passa pelos ajustes da mente, do corpo, dos valores e das atitudes na sociedade determinada pelo consumo de massa que ele chama de americanismo e fordismo.

Similarmente, Bauman (2010, p. 101) argumenta que com a destruição da cultura popular prémoderna, a educação se tornou uma demanda para converter e cultivar almas e corpos humanos, "uma tentativa desesperada de regulamentar o desregulamentado, de introduzir ordem numa realidade social

\footnotetext{
${ }^{4}$ Ibidem.

${ }^{5}$ Ibidem.
}

que antes já fora expropriada dos seus próprios dispositivos de auto-ordenamento". A educaçáo tornou-se parte de uma engrenagem que move a divisão social do trabalho, enfim, tornou-se um imperativo para sociedade moderna.

A análise de Bauman (2010) sobre a educação leva em consideração a transição do que ele denomina de sociedade pré-moderna para uma sociedade moderna. Ele argumenta sobre a necessidade de uma reformulação dos padróes comportamentais humanos, um ajuste dos corpos, a transformação de sujeitos em objetos uniformes; a implementação de uma nova ordem: a vigilância assimétrica.

É nesse contexto que a educação se torna um constituinte irremovível do poder. Os detentores de poder devem, por um lado, saber o que é bem comum e qual padrão de conduta se ajusta a ele e, por outro, saber como induzir a conduta e como garantir sua permanência. Bauman (2010, p. 75) afirma que, para garantir estas capacidades, é necessário que eles se apropriem de um certo saber que outras pessoas não possuem, ou seja, "o poder necessita do saber; o saber empresta legitimidade e eficácia (não necessariamente desconectadas) ao poder. Possuir saber é poder".

Por não formarem um grupo homogêneo, os intelectuais ganham funções distintas na organização da hegemonia social e no domínio estatal. Há a necessidade de uma gradação de qualificaçôes, seja de caráter diretivo e organizativo/administrativo, seja de caráter manual e instrumental. Segundo Gramsci (1982, p. 11-12),

De fato, a atividade intelectual deve ser diferenciada em graus, inclusive do ponto de vista intrínseco; estes graus, nos momentos de extrema oposição, dão lugar a uma verdadeira e real diferença qualitativa: no mais alto grau, devem ser colocados os criadores das várias ciências, da filosofia, da arte, etc.; no mais baixo, os "administradores" e divulgadores mais modestos da riqueza intelectual já existente, tradicional, acumulada.

Para Bauman (2010, p. 102) "A ideia de educação significava o dever e direito do Estado de formar (mais bem expresso do conceito alemão Bildung) seus cidadãos e guiar sua conduta. Representava o conceito e a prática de uma sociedade administrada". Dado que o Estado era o macroeducador, tanto o educador quanto o processo educativo não eram autônomos. 
Para haver mudança era necessário que Estado e mestres fossem re-educados (NOSELLA, 2010). Neste contexto, a formaçáo dos intelectuais ganha destaque, já que a educação e seus instrumentos de difusão disseminam as ideologias dominantes. E por serem contraditórias, contribuem com a manutenção ou instauração de uma nova ordem.

Se por um lado, Gramsci compreende que pode haver uma mudança na funçáo dos intelectuais tradicionais, que podem se tornar orgânicos no engajamento político no interior de um grupo social e/ou fora dele, por outro, Brauman identifica uma mutação do papel social dos intelectuais (representado pela metáfora do legislador na sociedade moderna) para outro tipo de intelectual (representado pela metáfora do intérprete na sociedade pós-moderna).

A fim de explicar este novo papel dos intelectuais, Bauman destaca alguns elementos característicos da sociedade pós-moderna, tais como: o controle do mercado, a cultura do consumo e a autonomia das instituiçóes de pesquisa e aprendizagem especializadas, que não necessitam de validação de um grupo de intelectuais, pois criam suas próprias regras. $\mathrm{O}$ papel do intelectual como legislador cai por terra, por um lado, porque há ausência de lugares a partir dos quais os legisladores possam fazer afirmações competentes e, por outro, porque há uma urgência por especialistas em tradução de tradições culturais, em uma conversação civilizada.

Este é, naturalmente, um tipo de reação ao conflito permanente de valores para o qual os intelectuais, graças às suas habilidades discursivas, estão mais bem preparados. Falar com as pessoas em vez de brigar com elas; entendê-las em vez de repudiá-las ou aniquilá-las como mutantes; incrementar sua própria tradição bebendo com liberdade na experiência de outros grupos, em vez de excluí-los do comércio de ideias. É isso que a tradição própria dos intelectuais, constituída pelas discussóes em curso, prepara as pessoas para fazerem bem. A arte da conversação civilizada é algo de que o mundo pluralista necessita com premência. Ele só pode negligenciar essa arte às suas expensas. Conversar ou sucumbir ${ }^{6}$

Bauman (2010) examina a relação entre educação, sociedade e a função dos intelectuais como legis-

${ }^{6}$ Ibidem, p. 197 ladores no mundo moderno e a emergência do novo papel dos intelectuais, que ele melhor caracteriza pela metáfora dos intérpretes no mundo pós-moderno. Ademais, a análise de Gramsci (1982) prioriza a formação dos intelectuais, em especial dos intelectuais orgânicos, como uma atividade política e revolucionária. Tal visão ainda é atual, uma vez que temos como herança os intelectuais tradicionais e orgânicos, ainda que de modo mascarado nas novas relações sociais. A partir do que foi até aqui exposto, defendemos que fazer uma incursão nos conceitos de intelectuais propostos por Gramsci e Bauman nos ajuda a refletir sobre as relaçōes existentes entre currículo, conhecimento e formaçáo dos intelectuais numa perspectiva histórica e "explicar o modo como determinadas formas de conhecimento são canonizadas e a forma como o poder as reifica e calcifica" (KINCHELOE, 2001, p. 10), tal como veremos a seguir.

\section{SOBRE CONHECIMENTO E CURRÍCULO}

Currículo é um termo sob o qual as teorias curriculares não apresentam consenso. É um termo multifacetado que envolve complexas e contínuas discussôes. Não há nada intrinsecamente característico ao termo que possibilite a qualquer teoria defini-lo de forma plena e essencial, pois a plenitude, neste caso, é uma impossibilidade e a essência é desafiada por um transbordamento incessante de sentidos que levam a flutuaçóes e esvaziamentos permanentes do significante currículo no contexto de diferentes tendências teóricas. No entendimento de Lopes e Macedo (2011) a única coisa que pode haver sobre os sentidos que definem o currículo são acordos contingentes, precários e historicamente localizados.

O vínculo entre conhecimento e currículo está presente na maior parte das teorizaçóes curriculares. Como argumentam Lopes e Macedo (2011), o debate teórico sobre o currículo tem se caracterizado, predominantemente, como uma discussão acerca do processo de seleção, distribuição e organização do conhecimento escolar. Na afirmativa de Lopes (2012), a relação entre conhecimento e currículo tem sido táo fortemente tecida ao longo da história que o debate sobre currículo chega a se confundir, em diversos momentos, com o debate sobre os conhecimentos mais válidos. "Na definição do que é válido, a ciência com toda a legitimidade que lhe é socialmente conferida, tem ocupado lugar de destaque" (LOPES; MACEDO, 2012, p. 157) 
Lopes e Macedo (2011) asseveram que, de diferentes maneiras e com propósitos diversos, as teorizações sobre currículo têm se perguntado o que conta como conhecimento válido? Qual conhecimento a escola deve ensinar as novas gerações? Quais os critérios que devem orientar a seleção dos conteúdos escolares? Como devem ser organizados os conteúdos de ensino para distribuição aos diversos sujeitos nos diferentes níveis de escolarizaçáo? Essas perguntas têm encontrado respostas distintas nos registros de diferentes teorias curriculares. Ora as respostas se pautam em aspectos mais cientificistas, instrumentais e pragmáticos da educação e do conhecimento, ora em aspectos mais políticos, sociais e culturais que enfatizam as relaçôes de poder implicadas nos processos de produção do conhecimento e de seleção e organização do currículo escolar ou, ainda, essas perguntas são substituídas por outras questôes que possibilitam pensar o currículo como luta por significação cultural e discursiva. De acordo com as finalidades educacionais visadas em uma determinada época e contexto histórico e com a concepção de conhecimento defendida, essa relação tem sido enfocada sob diferentes perspectivas.

Sem a pretensão de desenvolver uma discussão mais exaustiva acerca das diferentes concepçôes curriculares e da forma como cada uma concebe o vínculo entre conhecimento, currículo e organização dos conteúdos escolares, passamos a pontuar, de forma breve, como essas questóes têm sido abordadas no âmbito de quatro perspectivas dominantes no campo das teorias do conhecimento e do currículo, situadas por Lopes e Macedo (2011; 2012), quais sejam: a perspectiva acadêmica, a perspectiva instrumental, a perspectiva progressivista e a perspectiva crítica.

A perspectiva acadêmica ${ }^{7}$ se pauta em regras e métodos de validaçáo de saberes. Somente quando um determinado enunciado atende aos critérios científicos de validação é que pode ser considerado um conhecimento. Sendo assim, só é conhecimento um saber que consegue passar nos testes de validação no contexto de uma disciplina acadêmica especializada. Nessa perspectiva, conhecimento é "um conjunto de concepçôes, ideias, fatos e conceitos, submetidos às regras e aos métodos consensuais de comunidades intelectuais específicas" (LOPES; MACEDO, 2011, p. 70).

\footnotetext{
${ }^{7}$ Os principais representantes da corrente acadêmica de conhecimento que defendem a identidade entre conhecimento científico e conhecimento escolar são os filósofos do conhecimento Paul Hist e Richard Peters e os cognitivistas Jerome Bruner e Joseph Schwab.
}

A resposta produzida por esta concepção acerca do conhecimento válido a ser ensinado pela escola é encontrada na lógica dos conhecimentos acadêmicos que constituem o cânone dos conhecimentos selecionados pela escola para garantir a transmissão às geraçôes mais novas da lógica do conhecimento produzido pela humanidade. Tem-se, assim, a ideia de currículo como um repertório de conhecimentos a serem ensinados, esses conhecimentos são derivações das disciplinas acadêmicas que os validam. Fica claro nessa perspectiva, binarismos que impóem a cisão entre saberes cotidianos e conhecimentos científicos; saberes narrativos e ciência; conhecimento formal e informal, criando, hierarquizaçóes entre as diferentes formas de compreender e significar o mundo, sendo a ciência o conhecimento válido que merece ser socialmente legitimado e prestigiado.

A perspectiva instrumental se identifica com a perspectiva acadêmica na medida em que também entende o conhecimento legítimo como aquele que atende às regras e aos métodos das disciplinas acadêmicas. A distinção entre a perspectiva acadêmica e a instrumental está na finalidade conferida a esses conhecimentos no processo de formação das pessoas. Para a primeira, o conhecimento tem como principal referência à razão instrumental, que é a razão que busca sua legitimidade pelo atendimento eficiente a determinados fins. Os principais representantes dessa corrente de pensamento curricular são Bobbit e Tyler que, guardadas as devidas diferenças entre o pensamento desses teóricos, constituem a base para a concepçáo instrumental de currículo. Nas consideraçôes de Lopes e Macedo (2011; 2012), esta foi a corrente que produziu a resposta mais duradoura para os questionamentos anteriormente mencionados, exercendo forte influência na definição de critérios para a seleção, organização e avaliação do conhecimento escolar até os dias de hoje.

Nessa tendência a escola é compreendida como uma instituição que tem como finalidade formar cidadãos capazes de gerar benefícios mais amplos para a sociedade. Visando essa finalidade, o currículo deve se constituir de uma seleção de conhecimentos cientificamente legitimados, mas com validade para a formação de habilidades e de conceitos necessários à produtividade social e econômica. $\mathrm{O}$ conhecimento relevante a ser ensinado deve ser aquele capaz de ser traduzido em competências, habilidades, conceitos e desempenhos passíveis de serem transferidos e aplicados em contextos fora da escola (LOPES; MACEDO, 2012). 
As autoras identificam a perspectiva progressivista, identificada com uma concepçáo pragmática de conhecimento, tem como seu maior representante o educador americano John Dewey. A teoria do conhecimento formulada por Dewey preconiza que qualquer campo do conhecimento humano representa um corpo de verdades a ser utilizado para a descoberta de novos problemas e pesquisas. Em uma perspectiva pragmática, "o conhecimento deve favorecer a melhor execução das atividades humanas" (LOPES; MACEDO, 2011, p. 75). Nesse caso, o conhecimento precisa ser embasado na experiência, visando à soluçâo de problemas concretos. Diferentemente da perspectiva instrumental, que também defende o caráter utilitário do conhecimento, o papel da educação nấo deve ser o de preparar as pessoas para desenvolverem competências associadas ao funcionamento do sistema produtivo. As finalidades educacionais a serem perseguidas pela escola estão relacionadas ao bem -estar da humanidade e à possibilidade de construção da democracia por meio da ação de escolarizaçấo.

Essa perspectiva se aproxima da perspectiva acadêmica no sentido da manutenção da referência aos saberes disciplinares acadêmicos. Porém, o seu afastamento se dá ao introduzir a ideia de que o currículo não pode ser dependente apenas da lógica disciplinar. O currículo tem que ser construído tendo em vista o caráter psicológico do conhecimento. Isso significa que o conhecimento científico não tem valor em si mesmo, mas a sua validade está no significado que pode ter para a experiência de vida de cada estudante. Para Dewey o conhecimento deve atender primeiramente aos princípios psicológicos para depois atender aos princípios lógicos. O critério básico para a seleção dos conhecimentos que devem fazer parte do currículo é o interesse dos alunos e da vida contemporânea. Dessa maneira, conhecimento escolar não é equivalente a conhecimento científico-acadêmico e, embora se relacione com este, tem especificidades que devem ser observadas na constituição das matérias escolares. Assim, Dewey, advoga por um conhecimento escolar próprio, sem abalar, no entanto, a crença na legitimidade do conhecimento científico e na importância de sua referência para composição do currículo.

A perspectiva crítica passa a questionar a centralidade do conhecimento acadêmico-científico e a suposta neutralidade com que esse conhecimento é inserido no currículo. A perspectiva crítica denuncia as relaçóes de poder implicadas no processo de seleção, distribuição e organização dos conteúdos de ensino, considerando que há um vínculo entre a superioridade conferida aos conhecimentos científicos privilegiados pelo currículo e a manutenção das desigualdades sociais e das hierarquias de classes.

Lopes e Macedo (2011) refletem que é por intermédio das teorias críticas que o conhecimento deixa de ser considerado um dado neutro. Para os diferentes autores filiados a essa perspectiva ${ }^{8}$ não cabe apenas discutir o que selecionar, quais critérios utilizar nessa seleção, mas é preciso questionar os modos como o conhecimento hegemônico é produzido e ao mesmo tempo problematizar por que determinados conhecimentos são selecionados e outros não e as relaçóes de poder implicadas na seleção e legitimação do mesmo. Estas perguntas foram colocadas por Michael Young no nascimento da Nova Sociologia da Educação, na Inglaterra na década de 1970. Na perspectiva dos discursos curriculares críticos, a preocupação central não está na validade epistemológica do conhecimento, não cabe somente discutir o que selecionar e como organizar eficientemente o currículo. Assim as questôes básicas do currículo se tornam: Por que determinados conhecimentos são considerados importantes e outros não? Quais os interesses que guiam a seleção de determinados conhecimentos? Quais são as relações de poder envolvidas no processo de seleção de um currículo particular? Quem os define e em favor de quem são definidos? Que culturas são legitimadas e que culturas são deslegitimadas? Esta perspectiva busca compreender por quais mecanismos de poder os saberes são classificados, hierarquizados e desigualmente distribuídos na escola por meio do currículo. O grupo de teorizaçóes críticas focaliza como a estrutura político-econômica e social atua no processo de seleção e legitimação do conhecimento considerado válido, assim como busca investigar os modos pessoais de dar significado aos diferentes saberes.

Numa perspectiva crítica, de viés gramsciano, assumida por autores como Aplle (1997; 1999; 2000), a análise de cunho econômico deve ser complementada com uma abordagem cultural e ideológica do currículo, a fim de levar a um entendimento mais adequado das complexas maneiras pelas quais as relaçóes econômicas, sociais, políticas, de raça e de gênero se reproduzem no contexto de uma sociedade desigual. O foco do autor são as mediaçóes ideológicas e cul-

\footnotetext{
${ }^{8}$ Dentre os principais autores da perspectiva crítica que se dedicam à discussão da relação entre conhecimento e currículo estão os ingleses Michael Young, Ivor Goodson e Basil Bernstein e o americano Michael Apple.
} 
turais que existem entre as condições materiais e a formação da consciência dos indivíduos. Apoiado nas noçóes gramscianas de ideologia e hegemonia e no conceito de tradiçáo seletiva, tais como discutidos por Raymond de Williams, Apple (2000) assevera que o currículo não é uma montagem neutra de conhecimentos, sempre parte da seleção contestada de uma cultura mais ampla, da seleção feita por alguém, da visão que algum grupo tem sobre o que é o conhecimento legítimo.

A tradição seletiva cria uma cultura humana geral como registro histórico de uma dada sociedade, esse mecanismo envolve uma série de exclusóes e a rejeiçâo de áreas consideráveis da cultura vivida. Assim, a cultura selecionada dentro de uma tradição seletiva se identifica com o conhecimento específico de determinados grupos dominantes, este conhecimento é o que é definido como o conhecimento oficial e socialmente legítimo, é aí que se encontra o caráter seletivo da tradição. $\mathrm{O}$ conhecimento hegemônico, fruto da tradição seletiva, não é simplesmente imposto, mas é hegemonizado via um conjunto de significados e práticas culturais e ideológicas que saturam o social e a consciência e são incorporados nas práticas cotidianas como senso comum. Quanto maior a capacidade do conhecimento hegemônico se constituir como senso comum, mais facilmente exerce sua hegemonia. Para Apple (1997) a política do conhecimento oficial é resultado de acordos ou compromissos estabelecidos em diversos níveis, desde o nível das políticas de Estado até o nível das práticas cotidianas das escolas. Desta forma, o currículo escolar recria a hegemonia ideológica de determinados grupos não somente por meio dos conhecimentos oficializados do currículo prescrito, mas também por meio das interaçôes que se estabelecem nas práticas cotidianas das escolas em que as normas, valores e crenças das classes dominantes são naturalizadas e assumidas como uma espécie de senso comum (APPLE, 1999).

Para Apple, o currículo escolar é um dos principais agentes de transmissão da cultura dominante, que ao reproduzir as relaçóes de dominação econômica e cultural, ao mesmo tempo, garante a hegemonia do projeto social das classes dominantes. Apple analisa que a relação entre pensamento e cultura não podem ser determinadas pelas relaçōes econômicas de forma tâo determinista, pois tal determinaçâo se dá numa rede bem mais complexa de relaçóes que são mediadas pela ação humana. Embora reconheça que a cultura não é um mero reflexo das práticas econômi- cas, o autor não deixa de concordar que a hegemonia cultural acaba tendo suas raízes na economia. Nesse sentido, o currículo escolar, na sua dimensão oficial e oculta, funciona náo apenas como mecanismo de reprodução da dominação econômica, mas, por meio de mecanismos ideológicos, reproduz a dominação cultural e simbólica de forma muito menos evidente e mais eficaz. Os conhecimentos dominantes conseguem se hegemonizar ao serem naturalizados como representação legítima da cultura humana e incorporados como senso comum pelas classes populares.

Indubitavelmente, as teorizaçôes curriculares críticas aqui mencionadas têm o mérito de buscar compreender o currículo como uma construção social e histórica e de desnaturalizar as relaçôes de poder que permeiam o processo seleçáo, legitimação e hegemonização de determinados conhecimentos no currículo escolar. Isso possibilita perceber o currículo como uma prática de poder, como lugar de disputas por significação, como um campo que está demarcado, nos termos de Foucault, por uma relação de saber-poder. Nesse sentido, não há nenhuma possibilidade de pensar o currículo como uma seleção neutra e desinteressada de conhecimentos, centrado apenas em critérios científicos e epistemológicos. O currículo, na perspectiva das teorias críticas se torna um campo contestado, produto de lutas e conflitos entre interesses divergentes que envolvem disputas em torno de questôes econômicas, culturais, de classe e, mais recentemente, também de questôes de raça e de gênero.

As contribuiçôes das teorias críticas para o campo do currículo são inegáveis, sobretudo, no sentido de desestabilizar os discursos hegemonizados pela racionalidade técnica, problematizar as relaçóes de poder implicadas na seleçáo do conhecimento escolar e denunciar as desigualdades e exclusóes materiais e simbólicas que o currículo é capaz de produzir e reproduzir. Entretanto, ao enfatizar o currículo como decorrente das relaçóes econômicas, em última instância, mesmo quando outras dinâmicas como a cultura, as relaçôes de raça e gênero são inseridas, as teorias críticas tendem a fortalecer uma ideia centralizada de poder definido como consequência das assimetrias econômicas e de classe. Poder, na perspectiva de alguns estudos críticos, é compreendido como uma relação necessária de opressão exercida por um polo dominante sobre um polo dominado, que tem na estrutura econômica a sua configuração determinante. A sociedade é concebida como um 
todo estruturado capaz de definir as posições fixas dos sujeitos ao nível das relaçóes de produçáo e das hierarquias de classes. As identidades políticas são vistas como essencializadas, fixadas de uma vez por todas como um dado imutável, anteriormente ao próprio processo político. A própria noção de cultura fica subjugada ao econômico, mesmo quando é enfatizado que a dominação cultural e ideológica se dá por mediaçôes mais complexas que envolvem negociações e acordos de natureza mais simbólica do que material.

\section{CONHECIMENTO E CURRÍCULO NA FORMAÇÃO DOS INTELECTUAIS}

O exercício da função de intelectual requer um processo formativo que se estabelece por meio da educação formal e da educaçáo informal. Gramsci (1982) analisa que para cada grupo social há um tipo ideal de intelectual que atende aos interesses daquele grupo. A criação de novos intelectuais requer a formação de um pensamento científico e a inculcação de atitudes que se faz de forma privilegiada por meio dos processos de escolarização.

Numa perspectiva acadêmica do currículo, os conhecimentos válidos para serem ensinados na escola devem estar ligados umbilicalmente aos conhecimentos acadêmicos. Essa ligação protagoniza os que exercem as profissóes intelectuais (BAUMAN, 2010), pois são os cientistas, filósofos e especialistas de áreas de conhecimento que determinam os conteúdos que devem ser considerados legítimos e, por isso, devem constituir os programas de ensino. Neste contexto, há uma tendência em abandonar as finalidades utilitárias e práticas das disciplinas escolares em favor de uma forma acadêmica e universitária que reflete definiçōes hegemônicas do conhecimento (GOODSON, 2001).

Segundo Goodson (2001, p. 171), "o currículo acadêmico tem e sempre teve, historicamente, um propósito vocacional, mas a preparaçấo destina-se ás profissões de estado elevado". O currículo do ensino médio brasileiro carrega este propósito desde sua origem no antigo ensino secundário, dado que, com a criação dos Cursos Jurídicos, em 1827, era necessário pensar em como selecionar e preparar os alunos para o ensino superior, ou seja, havia um propósito de pensar num currículo voltado para escolarizaçâo dos intelectuais que atuariam na sociedade como legisladores.
Outra dimensão a ser analisada é a influência das igrejas na educaçáo, por meio das escolas confessionais, cujo currículo é elaborado por uma camada de intelectuais tradicionais, representantes de uma determinada ordem religiosa. São estes intelectuais, inspirados nos preceitos religiosos, que determinam qual o conhecimento deve ser ensinado, como deve ser ensinado e que atitudes devem inculcadas nos jovens. Associamos esta dimensão à perspectiva instrumental, uma vez que o currículo destas escolas, embora não se restrinjam à educaçáo religiosa, tem como objetivo a conversão dos alunos. Como exemplo, citamos os dados apresentados por Shunemann (2009) sobre uma rede educacional protestante no Brasil, que mostram que os preceitos religiosos desta rede orientam o ensino das disciplinas, inclusive na re-elaboração de conteúdos.

A perspectiva instrumental náo se restringe às escolas confessionais, pois abrange todas as escolas que enfatizam um currículo prático, que prioriza a formação de habilidades e a inculcação de determinadas atitudes. O conhecimento acumulado e sistematizado aliado à formação de atitudes e comportamentos tem o poder de lapidar, não somente um novo cristáo, mas também novos dirigentes, ou seja, os intelectuais como legisladores.

Os fundadores das escolas de elite nunca acharam que deveriam definir o currículo apenas em termos gerais, enquanto conjunto de disciplinas acadêmicas. Eles agiram de forma bastante semelhante aos educadores católicos que acreditavam que um currículo eficaz incluía a formação do caráter, ou doutrinação ideológica e a disciplina estrita. Neste sentido, o currículo é uma experiência universal e não uma base conhecimento concreta (GOODSON, 2001, p. 197).

O interesse é a modificação do comportamento através da disciplina, que impóe certos tipos de condutas; pela manipulação de rituais e dos símbolos, que cria determinadas lealdades coletivas; e pela regulaçáo da "estrutura profunda", que procura controlar as necessidades emocionais e somáticas dos estudantes?.

$\mathrm{Na}$ busca pelo consenso espontâneo das massas torna-se necessário adequar as necessidades individuais ao meio social, desta forma, é cada vez mais imperativo que sejam formados sujeitos capazes de

\footnotetext{
9 ibidem
} 
adaptar-se às demandas da sociedade em diferentes contextos. Situamo-nos na perspectiva progressivista, uma perspectiva não crítica, na qual a educação tem papel decisivo na conformação da sociedade evitando sua desagregação (SAVIANI, 2003). Nesta perspectiva, enfatiza-se um currículo voltado para formação de grandes massas de intelectuais de forma estandardizada, tanto na qualificação intelectual quanto na psicológica (GRAMSCI, 1982).

Nesse contexto, as escolas de todo tipo são valorizadas, por serem instituiçóes formadoras dos diversos tipos de intelectuais. Se compreendermos o currículo como projeto de formação que se materializa num determinado tempo e espaço (PACHECO, 2014), identificamos que na transição do mundo moderno para o pós-moderno é necessário a formação de novos intelectuais nos campos econômicos, sociais, culturais e ideológicos. A educação escolar expõe as marcas curriculares de uma formação voltada para a elaboração de intelectuais tradicionais e legisladores, ao mesmo tempo em que abre caminhos para a formação de novos tipos de intelectuais.

Numa perspectiva crítica, de viés gramsciano, é necessária a formação de um quadro de intelectuais engajados social e politicamente na luta pelos interesses da classe trabalhadora. Estes são os intelectuais orgânicos, os quais se inscrevem em uma configuraçâo histórica que não é mais a tradicional.

$\mathrm{Na}$ perspectiva de Bauman (2010, p. 197), é necessário a formação de intelectuais "especialistas em tradução entre tradiçôes culturais", pois já não há lugares para intelectuais enquanto legisladores na sociedade pós-moderna. Nesse contexto, a escola enquanto um microcosmo da sociedade exerce importante papel, pois no seu interior há um encontro de culturas que envolve a aceitação, a negociação, a contestação e a reinvenção de significados (RIBEIRO, 2013). Segundo Ribeiro (2013, p. 106) "a traduçấo cultural não é mera apropriação de aspectos de certa cultura, mas um processo que permite às pessoas avaliarem suas referências, normas e valores, abandonando aquilo que é habitual e natural, e anexando o que é diferente, estranho e até, excêntrico". A partir desta compreensão, esta autora anuncia a possibilidade de um currículo tradutório:

Do ponto de vista contextual a lógica cultural do capitalismo tardio e as marcas impressas pela globalizaçáo econômica e cultural. Do contexto epistemológico, o currículo é atingido pela cri- se da ciência moderna, pela virada linguística, o que gera a crise na teoria curricular crítica e "desprotege" o flanco, colocando no front outras noçôes de educaçẫo, escola, conhecimento, sujeito, razão, tempo, espaço, realidade; noçóes abertas, fluidas e fragmentadas. ${ }^{10}$

Ou seja, isso coloca que uma mudança na concepçáo de intelectuais associada a um determinado contexto social, econômico e político tem implicações diretas na relação entre conhecimento e currículo, pois a formação de novos intelectuais envolve a aceitação e contestação de conhecimentos já cristalizados, a negociaçáo de novos conhecimentos e novos modos de significaçáo do currículo.

\section{CONSIDERAÇÓES FINAIS}

Vimos que um percurso histórico não factual e não linear pelo conceito de intelectuais nos ajuda a compreender as relaçóes existentes entre conhecimento e currículo. Depreendemos que a formação dos intelectuais de diversos tipos e em distintos contextos imprimiu traços no currículo que ainda permeiam nosso contexto educacional. Tais traços incluem a seleção de determinados conhecimentos considerados essenciais que se cristalizaram ao longo do tempo e a formação de atitudes exigidas por interesses hegemônicos. Porém, vimos também que tais conhecimentos e atitudes vêm sendo questionados nas perspectivas críticas e pós-críticas do currículo e que novas possibilidades de compreensão do currículo têm implicações nos modos de ressignificação do conhecimento.

Embora os conceitos de intelectuais compreendidos como tradicionais ou legisladores não deem conta dos problemas emergentes da sociedade atual, não podemos negar que o legado de sua formação ainda permanece nos currículos das escolas. Arriscamos dizer que esse legado são heranças curriculares de uma formação que têm sido passadas de geração a geração, muitas vezes reelaborada e acoplada a novos elementos e novos interesses. Acreditamos ainda que para a formação de novos intelectuais, sejam eles orgânicos ou intérpretes, serão necessários novos modos de pensar o currículo e, consequentemente, a produção/concepção de novos conhecimentos.

10 ibidem, 106, grifo nosso. 


\section{REFERÊNCIAS}

ABUD, K. M. A história e o ensino temático. In: MONTEIRO, J. M.; BLAJ, I. (Org). Histórias \& Utopias. São Paulo: ANPUH, 1996, p. 492-501. Textos apresentados no XVII Simpósio Nacional de História Disponível em: http://anais.anpuh.org/?p=16734Acessoem: 20/06/2013

APPLE, M. W. Conhecimento Oficial: a educação democrática numa era conservadora. Petrópolis: Vozes, 1997.

APPLE, M. W. Ideologia e currículo. 2. ed. Porto Alegre: Artmed, 1999.

APPLE, M. W. Política cultural e educaçáo. São Paulo: Cortez, 2000.

BAUMAN, Z.Legisladores e intérpretes: sobre modernidade, pós-modernidade e intelectuais. Rio de Janeiro: Zahar, 2010.

FERREIRA, J. R. R. Expansáo da escola básica e a relaçáo capital, trabalho e educaçáo no Brasil dos anos 1970. 125 f. 2011. Tese (Doutorado em Educação) - Faculdade de Educação, Universidade Federal de Goiás, Goiânia, 2011. Disponível em: https://ppge.fe.ufg.br/up/6/o/ Joao_Roberto_Resende_Ferreira_completa_24-11-2011. pdf?1335452208 Acesso em: 05 maio 2015

GOODSON, I. O currículo em mudança: estudos na construção social do currículo. [S.l.]: Porto, 2001.

GRAMSCI, A. Os intelectuais e a organizaçáo da cultura. Rio de Janeiro: Civilização Brasileira, 1982.

KINCHELOE. J. L. Introdução. In: GOODSON, I. O currículo em mudança: estudos na construção social do currículo. [S.1.]: Porto, 2001.

LOPES, A. C.; MACEDO, E. Teorias de Currículo. São Paulo: Cortez, 2011.

LOPES, A. C.; MACEDO, E. Currículo e cultura: o lugar da ciência. In: LIBÂNEO, J. C.; ALVES, N. (Org.). Temas em Pedagogia: diálogos entre didática e currículo. São Paulo: Cortez, 2012. v. 1, p. 152-166.

LOPES, A. C. Políticas de integraçáo curricular. Rio de Janeiro: EdUERJ, 2008.

NEIRA, M. G.; LIPPI, B. G. Tecendo a colcha de retalhos: a bricolagem como alternativa para a pesquisa educacional. Educaçáo \& Realidade, Porto Alegre, v. 37, n. 2, p. 607625, maio/ago., 2012. Disponível em: <http://www.ufrgs. br/edu_realidade $>$ Acesso em: 14 jan. 2016

NOSELlA, P. A escola de Gramsci. 4. ed. São Paulo: Cortez, 2010.
PACHECO, J. A. Educaçáo, formaçáo e conhecimento. [S.1.]: Porto, 2014.

RIBEIRO, J. O. S. A traduçáo da tradiçáo em práticas curriculares no Colégio Estadual Paes de Carvalho. 205f. 2013. Tese (Doutorado em Educação) - Faculdade de Educação, Universidade Federal do Pará, Belém, 2013. Disponível em: http://www.ppged.belemvirtual.com.br/arquivos/File/joyce_tese2013_pdf.pdf Acesso em: 03 mar. 2013

SAVIANI, D. Pedagogia histórico-crítica: primeiras aproximaçôes. 8. ed. Campinas: Autores Associados, 2003. 